\title{
Qualidade da Carne de Cordeiros Santa Inês Terminados com Diferentes Dietas
}

\section{Marta Suely Madruga ${ }^{1}$, Wandrick Hauss de Sousa ${ }^{2}$, Maria D. Rosales ${ }^{3}$, Maria das Graças Glória Cunha $^{2}$, Jorge Luiz de Farias Ramos ${ }^{2}$}

\begin{abstract}
RESUMO - Foram avaliados os aspectos qualitativos da carne de cordeiros Santa Inês submetidos, na fase de terminação, a sistemas de alimentação diferenciados. Foram analisadas 24 pernas de cordeiros não-castrados, com idade de abate entre seis e dez meses, distribuídos eqüitativamente segundo as dietas recebidas: $\mathrm{T} 1$ = feno de capim-d'água + concentrado, T2 = feno de restolho de abacaxi + concentrado, T3 = palma + mistura, T4 = silagem de milho + concentrado. A utilização de quatro tipos de alimentos volumosos exerceu influência significativa sobre os teores de composição centesimal, cálcio, fósforo, colesterol, fosfolipídios, ácidos graxos saturados e poliinsaturados e nos parâmetros sensoriais da carne de ovinos Santa Inês. Os cordeiros alimentados com volumosos energéticos (T1, T2 e T4) apresentaram carnes com maiores concentrações lipídicas em $(6,93 ; 8,09$ e 8,38\%, respectivamente), melhor qualidade sensorial e maiores percentuais de ácidos graxos monoinsaturados (C18:1, C16:1, com médias de 41,38; 46,40; 43,15 e 3,44; 3,34; e 2,76\%, respectivamente). O uso de palma forrageira (T3) na alimentação dos cordeiros resultou em uma carne com teores de umidade, proteínas, fósforo, cálcio, colesterol e ácidos graxos saturados significativamente maiores em relação aos demais volumosos (T1, T2 e T4), porém com qualidade sensorial inferior.
\end{abstract}

Palavras-chave: análises químicas, carne ovina, dietas, palma, silagem de milho

\section{Quality of Santa Ines Lamb Meat Terminated with Different Diets}

\begin{abstract}
This study had the objective of evaluating the qualitative aspects of lamb meat from Santa Ines breed when submitted in the termination phase to different feeding systems. Twenty four legs from entire lambs with slaughter age from six to ten months were equally distributed among four different diets: T1 = capim-d'água hay + concentrate, $22=$ pineapple hay + concentrate, $\mathrm{T} 3$ = forage palm + mixture, $\mathrm{T} 4=$ maize ensilage hay + concentrate. The utilization of four different forager feeds resulted in significant difference among the percentages of centesimal composition, calcium, phosphorus, cholesterol, and phospholipid, saturated and unsaturated fatty acids and in the sensorial parameters of lamb meat. Lambs fed diet with high-energy forage (T1, $\mathrm{T} 2$ and $\mathrm{T} 3$ ) had meat with the highest percentages of fat $(6.93,8.09$ and $8.38 \%$, respectively), and monosaturated fatty acids (C18:1, C16:1, with average of $41.38,46.40$ and 43.15 and $3.44,3.34$ and $2.76 \%$, respectively), associated to a better sensorial quality. The use of forager palm (T3) in lamb feeding resulted in lamb meat with higher percentages of humidity, protein, phosphorus, calcium, cholesterol and saturated fatty acids in comparison with the others treatments (T1, T2 and T4), although this lamb meat had lower sensorial quality in relation to the meat obtained from the others treatments.
\end{abstract}

Key Words: chemical analysis, corn silage, diets, lamb meat, palm

\section{Introdução}

A ovinocultura tem-se apresentado como uma das opções do agronegócio brasileiro, em virtude de o Brasil possuir baixa oferta no consumo interno da carne ovina e dispor dos requisitos necessários para ser um exportador desta carne, como: extensão territorial, mão-de-obra de baixo custo, rebanho expressivo, entre outros.

A raça Santa Inês, denominada ovino deslanado, é apontada como uma alternativa promissora em cruzamentos para a produção de cordeiros para abate, por ter capacidade de adaptação, rusticidade e eficiência reprodutiva, baixa susceptibilidade a endo e a ectoparasitos. Além destas vantagens, não apresenta comportamento estacional (Sousa, 1987), exercendo importante papel na produção de proteína em áreas de clima seco, como o semi-árido do nordeste do Brasil. Pesquisas vêem sendo realizadas sobre influência dos fatores pré e pós-abate na qualidade da carne de ovinos Santa Inês. Bressan et al (2001) reportaram a influência do peso ao abate nos parâmetros físicoquímicos da carne de cordeiros Santa Inês e Perez et al. (2002), estudando o mesmo fator relataram o perfil de ácidos graxos, do colesterol e da composição química da carne de cordeiros Santa Inês.

\footnotetext{
${ }^{1}$ Professora, Departamento de Tecnologia Química e de Alimentos, Universidade Federal da Paraíba (DTQA/UFPB), Campus I, João Pessoa/PB, CEP 59.059-900. E-mail:msmadruga@uol.com.br

2 Pesquisador da EMEPA (Empresa Estadual de Pesquisa Agropecuária da Paraíba). Rua Eurípides Tavares, nํ210, Tambiá, CEP: 58.013290, João Pessoa/PB.

3 Mestre em Ciência e Tecnologia de Alimentos, PPGCTA/CT/UFPB.
} 
No semi-árido nordestino, a alimentação é fator limitante da produção de carne ovina. Nessa região, a base da alimentação animal é a caatinga, que sofre influência de duas estações distintas - a chuvosa e a seca. Durante a estação chuvosa, o alimento disponível é abundante e de boa qualidade nutricional, enquanto, na estação seca, a disponibilidade e a qualidade da forragem são reduzidas em virtude da lignificação da parede celular e do decréscimo de proteína bruta das plantas, escasseando a produção de alimentos (Simplício, 2001).

A terminação em confinamento com alimentação de elevado valor nutritivo constitui-se uma prioridade, quando o sistema de produção visa atingir níveis elevados de ganho de peso e a obtenção de carcaças de melhor qualidade. Entre os sistemas de terminação no nordeste, o confinamento é um método alternativo, para a obtenção de animais na entressafra (Perez, 2003).

Com a maior demanda por alimentos para composição das rações concentradas formuladas para as diversas categorias animais da ovinocultura, aumenta-se a procura por produtos que permitam boa performance animal e econômica aos sistemas intensivos de criação. Em função disso, a adoção de alimentos alternativos vem se destacando como excelente alternativa como componente energético para rações de ruminantes.

Considerando a importância da alimentação sobre o efeito na produção e nas características gerais da carne ovina, justifica-se a necessidade de estudos sobre a influência da alimentação na qualidade da carne de ovinos da raça Santa Inês, visando detectar sistemas de alimentação alternativos adaptáveis às condições de criação no semi-árido nordestino.

Avaliou-se, neste trabalho, a influência de quatro tipos de alimentos volumosos sobre os aspectos qualitativos da carne de ovinos Santa Inês.

\section{Material e Métodos}

Foram analisados o corte "perna" de 24 cordeiros da raça Santa Inês, machos, não-castrados, com peso inicial médio à aplicação dos tratamentos de $18,5 \pm 0,2 \mathrm{~kg}$, distribuídos em quatro grupos. Os tipos de alimentos volumosos fornecidos na fase de terminação foram: $\mathrm{T} 1=60 \%$ de feno de capim-d'água $+40 \%$ de concentrado; $\mathrm{T} 2=60 \%$ de feno de restolho de abacaxi $+40 \%$ de concentrado; $\mathrm{T} 3=60 \%$ de palma forrageira $+40 \%$ de uma mistura formulada com uréia (30\%), melaço (30\%), argila bentonita para controle do $\mathrm{pH}$ do rúmen do animal (20\%) e sal mineral (20\%); e T4 $=60 \%$ de silagem de milho $+40 \%$ de concentrado. O concentrado foi constituído de milho em grãos (68\%), farelo de soja $(20 \%)$, farelo de trigo (10\%) e sal mineral (2\%). As dietas foram formuladas de acordo com as recomendações do National Research Council (NRC, 1985) e foram fornecidas pela manhã (7 horas) e à tarde (15h30).

Os animais submetidos aos tratamentos T1, T2 e $\mathrm{T} 4$ foram abatidos com peso médio de $29,3 \mathrm{~kg}$ e idade de seis e a meses. Os animais do tratamento T3 foram abatidos com peso aproximado de $16,7 \mathrm{~kg}$ e idade de oito a dez meses, observando-se perda de peso para os ovinos deste grupo.

Os cordeiros foram submetidos a jejum hídrico de 24 horas e, em seguida, foram abatidos seguindo as normas vigentes do RIISPOA, observando-se, após o abate, o resfriamento das carcaças em câmara frigorífica a temperatura inferior a $5^{\circ} \mathrm{C}$ por 24 horas. As vinte e quatro peças, obtidas durante a desossa das carcaças, foram acondicionadas em sacos plásticos e armazenadas em freezer a $-18^{\circ} \mathrm{C}$, para estudos posteriores.

As pernas dos cordeiros foram descongeladas em geladeira convencional por 24 horas, coletando-se, seqüencialmente, as amostras para as análises. Para as análises químicas, diversos pedaços da perna foram amostrados e triturados em liquidificador até a obtenção de uma pasta homogênea. Diferentes pedaços da perna foram acondicionados em sacos plásticos até a realização das análises sensoriais e de cor, quando foram cortados segundo as metodologias pertinentes.

A medição de cor da carne ovina foi realizada segundo Muller (1980) em colorímetro MINOLTA Color reader CR-10, operando no sistema CIE (L* luminosidade, $\mathrm{a}^{*}$ intensidade de cor vermelha, $\mathrm{b}^{*}$ intensidade de cor amarela). Foram feitas três medições em diferentes pontos da amostra, que foi cortada em cubos de $5 \mathrm{~cm}$ de comprimento por $3 \mathrm{~cm}$ de largura e $2 \mathrm{~cm}$ de espessura.

As análises químicas realizadas foram de composição centesimal, de alguns minerais e de componentes lipídicos. Os teores de umidade, cinzas, proteínas e cálcio foram determinados segundo AOAC (2000) e as dosagens de fósforo total e ferro total, segundo Egan et al. (1981). As dosagens dos componentes lipídicos constaram de determinação de gordura total (Folch et al., 1957), de colesterol total (Bohac et al., 1988), de fosfolipídios totais (Egan et al., 1981) e de ácidos graxos (Hartman \& Lago, 1973). 
Para análise sensorial, realizou-se o teste da Escala Hedônica, com três repetições para cada tratamento, segundo Amarine et al. (1965), Larmond (1979) e Madruga et al. (2000). Porções de $200 \mathrm{~g}$ de carne ovina descongelada foram cortadas em cubos de $1 \mathrm{~cm}^{3}$ e cozidas em forno pré-aquecido a $200^{\circ} \mathrm{C}$ até que a temperatura interna da amostra atingiu $75^{\circ} \mathrm{C}$. Quatro cubos, escolhidos ao acaso, foram transferidos para um béquer pré-aquecido, codificado e coberto com vidro de relógio, para evitar perda de voláteis. O béquer contendo a amostra foi colocado em banhomaria, para manter a temperatura na faixa de $65-70^{\circ} \mathrm{C}$.

Uma equipe de 15 provadores treinados realizou as análises sensoriais. Cada atributo foi pontuado numa escala de 1 a 9, de forma que 1 referiu-se à condição menos favorável e 9 à mais favorável, em relação aos parâmetros sensoriais de aparência, odor ovino, odor de carne assada, textura, maciez, sabor e suculência. O formulário utilizado continha termos que variaram de muitíssimo bom a muitíssimo ruim; gostei muitíssimo a desgostei muitíssimo; extremamente intenso a extremamente fraco; extremamente macio a extremamente duro; extremamente seco a extremamente suculento.

Os dados foram analisados estatisticamente pela técnica paramétrica de análise de variância (ANOVA) do programa estatístico SPSS (Statistics Package for the Social Sciences), versão 6.0.1 (Stell \& Torrie, 1980). Os percentuais dos componentes lipídicos foram também submetidos à análise de Correlação de Pearson, cuja significância dos coeficientes (r) foi determinada pelo teste $\mathrm{t}$ de student a 5 e $1 \%$ de probabilidade (Stell \& Torrie, 1980).

\section{Resultados e Discussão}

Os valores médios encontrados para as análises químicas, físico-químicas e sensoriais da carne de ovinos Santa Inês estão listados na Tabela 1. O efeito de diferentes dietas na fase de terminação sobre a qualidade da carne ovina afetou significativamente ( $\mathrm{P}>0,05)$ os parâmetros químicos e sensoriais da carne, a exceção das concentrações de cinzas, ferro e dos componentes de cor $\left(L^{*}, a^{*}, b^{*}\right)$.

$\mathrm{O}$ maior teor de umidade correspondeu às amostras de carne provenientes de animais alimentados com palma forrageira (76 g/100 g), diferindo dos resultados regristrados para as carnes de animais alimentados com capim-d'água, restolho de abacaxi e silagem de milho (72,69 g/100 g, 71,43 g/100 g, 70,81 g/100 g, respectivamente). Comportamento semelhante foi ob- servado para proteína, cuja maior concentração foi detectada em ovinos alimentados com palma forrageira. Mesmo não havendo diferenças significativas para cinza entre as quatro dietas, observou-se que as concentrações individuais de alguns minerais, como cálcio e fósforo, foram significativamente superiores nas carnes de ovinos alimentados com palma forrageira. Por outro lado, o teor de lipídios foi o parâmetro de composição centesimal mais afetado pelo efeito das dietas analisadas, demonstrando que ovinos alimentados com palma forrageira apresentaram carne com teores de gordura reduzidos $(2,74 \mathrm{~g} /$ $100 \mathrm{~g}$ ), enquanto, nas demais dietas, as médias variaram de 6,93 a 8,38 g/100 g. Ovinos alimentados com os volumosos energéticos feno de capim-d'água, feno de restolho de abacaxi e silagem de milho apresentaram carnes com teores de lipídeos em maiores concentrações.

As médias obtidas para umidade, cinzas, gorduras e proteínas assemelham-se às reportadas por Sañudo et al. (1992), em cordeiros tipo ternasco, Zeola (2001, 2002), na raça Morada Nova, e Perez et al. (2002), na raça Santa Inês.

Os animais alimentados com palma forrageira apresentaram baixo teor de gordura na carne, que teve sua qualidade sensorial afetada, de modo que os atributos aparência, textura, maciez, sabor e suculência receberam as menores notas dos provadores, em comparação aos da carne dos demais tratamentos. Os resultados comprovaram também que a utilização de feno de capim-d'água ou feno de restolho de abacaxi como volumosos na alimentação de ovinos favoreceu as qualidades sensoriais da carne ovina, uma vez que as maiores notas para os parâmetros sensoriais foram atribuídas à carne dos ovinos que consumiram estes volumosos. "Odor ovino" mais evidente foi detectado nos animais alimentados com silagem de milho, coincidindo com aqueles que apresentaram teores de lipídeos mais elevados na carne, confirmando-se a importância dos lipídeos na formação do aroma cárneo característico da espécie (Mottram, 1998; Madruga et al, 2002). Madruga (1997) afirma que o aroma e o sabor característicos da carne estão diretamente relacionados ao teor de gordura presente no músculo, fato observado na presente pesquisa em relação ao odor ovino mais intenso na amostra que apresentou maior teor de gordura, aquela com dieta a base de silagem de milho. 
Tabela 1 - Resultados químicos, físico-químicos e sensoriais da carne de ovinos Santa Inês Table 1 - Chemical, physical-chemical and sensorial results from Santa Inez lamb meat

\begin{tabular}{|c|c|c|c|c|}
\hline \multirow[b]{2}{*}{$\begin{array}{l}\text { Componente } \\
\text { Component }\end{array}$} & \multicolumn{4}{|c|}{ Dietas (Diets) } \\
\hline & $\begin{array}{c}\text { Capim-d'água }{ }^{1} \\
\text { (T1) } \\
\text { Capim-d'água } \\
\text { hay (T1) }\end{array}$ & $\begin{array}{l}\text { Restolho de } \\
\text { abacaxi' (T2) } \\
\text { Pineapple } \\
\text { hay (T2) }\end{array}$ & 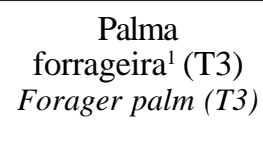 & $\begin{array}{c}\text { Silagem de } \\
\text { milho' (T4) }^{1} \\
\text { Maize ensilage } \\
\text { hay (T4) }\end{array}$ \\
\hline $\begin{array}{l}\text { Umidade }(\mathrm{g} / 100 \mathrm{~g}) \\
\text { Moisture }(\mathrm{g} / 100 \mathrm{~g})\end{array}$ & $72,69^{b} \pm 2,79$ & $71,43^{b} \pm 1,68$ & $76,07^{a} \pm 1,13$ & $70,81^{b} \pm 2,66$ \\
\hline $\begin{array}{l}\text { Cinzas }(\mathrm{g} / 100 \mathrm{~g}) \\
\text { Ash }(\mathrm{g} / 100 \mathrm{~g})\end{array}$ & $1,20^{\mathrm{a}} \pm 0,21$ & $1,08^{\mathrm{a}} \pm 0,05$ & $1,11^{\mathrm{a}} \pm 0,11$ & $1,05^{\mathrm{a}} \pm 0,12$ \\
\hline $\begin{array}{l}\text { Proteínas }(\mathrm{g} / 100 \mathrm{~g}) \\
\text { Total protein }(\mathrm{g} / 100 \mathrm{~g})\end{array}$ & $20,18^{\mathrm{ab}} \pm 0,75$ & $19,59^{b} \pm 0,36$ & $21,06^{\mathrm{a}} \pm 0,98$ & $20,51^{\mathrm{ab}} \pm 0,74$ \\
\hline $\begin{array}{l}\text { Lípidos }(\mathrm{g} / 100 \mathrm{~g}) \\
\text { Fat }(\mathrm{g} / 100 \mathrm{~g})\end{array}$ & $6,93^{\mathrm{a}} \pm 3,22$ & $8,09^{a} \pm 2,27$ & $2,74^{\mathrm{b}} \pm 1,26$ & $8,38^{\mathrm{a}} \pm 3,48$ \\
\hline $\begin{array}{l}\text { Cálcio (mg/100 g) } \\
\text { Calcium (mg/100 g) }\end{array}$ & $5,52^{\mathrm{ab}} \pm 1,42$ & $5,55^{\mathrm{ab}} \pm 0,54$ & $6,98^{\mathrm{a}} \pm 1,01$ & $5,06^{\mathrm{b}} \pm 0,59$ \\
\hline $\begin{array}{l}\text { Ferro }(\mathrm{mg} / 100 \mathrm{~g}) \\
\text { Iron }(\mathrm{mg} / 100 \mathrm{~g})\end{array}$ & $2,07^{a} \pm 0,89$ & $2,48^{a} \pm 0,91$ & $2,08^{\mathrm{a}} \pm 0,93$ & $1,81^{\mathrm{a}} \pm 0,55$ \\
\hline $\begin{array}{l}\text { Fósforo }(\mathrm{mg} / 100 \mathrm{~g}) \\
\text { Phosphorus }(\mathrm{mg} / 100 \mathrm{~g})\end{array}$ & $178,89^{\mathrm{b}} \pm 19,58$ & $204,22^{\mathrm{ab}} \pm 9,27$ & $215,99^{\mathrm{a}} \pm 29,23$ & $176,30^{\mathrm{b}} \pm 14,77$ \\
\hline $\begin{array}{l}\text { Fosfolipídios }(\mathrm{mg} / 100 \mathrm{~g}) \\
\text { Phospholipids }(\mathrm{mg} / 100 \mathrm{~g})\end{array}$ & $15,88^{b} \pm 2,72$ & $21,67^{a} \pm 2,42$ & $16,88^{b} \pm 1,14$ & $13,39^{b} \pm 2,25$ \\
\hline $\begin{array}{l}\text { Colesterol }(\mathrm{mg} / 100 \mathrm{~g}) \\
\text { Cholesterol }(\mathrm{mg} / 100 \mathrm{~g})\end{array}$ & $57,37^{\mathrm{a}} \pm 7,03$ & $46,72^{\mathrm{b}} \pm 6,32$ & $57,80^{\mathrm{a}} \pm 4,04$ & $44,10^{b} \pm 5,71$ \\
\hline $\begin{array}{l}\mathrm{L}^{*} \\
\mathrm{a}^{*}\end{array}$ & $\begin{array}{c}40,70^{\mathrm{a}} \pm 4,43 \\
14,22^{\mathrm{a}} \pm 1,68\end{array}$ & $\begin{array}{l}42,96^{\mathrm{a}} \pm 1,96 \\
12,81^{\mathrm{a}} \pm 1,24\end{array}$ & $\begin{array}{r}40,18^{\mathrm{a}} \pm 0,92 \\
13,19^{\mathrm{a}} \pm 1,64\end{array}$ & $\begin{array}{l}39,76^{\mathrm{a}} \pm 1,88 \\
13,43^{\mathrm{a}} \pm 0,35\end{array}$ \\
\hline$b^{*}$ & $9,76^{\mathrm{a}} \pm 2,44$ & $10,16^{\mathrm{a}} \pm 0,64$ & $9,04^{\mathrm{a}} \pm 0,12$ & $9,29^{\mathrm{a}} \pm 1,36$ \\
\hline $\begin{array}{l}\text { Aparência } \\
\text { Appearance }\end{array}$ & $7,72^{\mathrm{a}} \pm 0,72$ & $7,80^{a} \pm 0,66$ & $7,17^{\mathrm{b}} \pm 0,96$ & $7,43^{\mathrm{ab}} \pm 1,31$ \\
\hline $\begin{array}{l}\text { Odor ovino } \\
\text { Lamb aroma }\end{array}$ & $4,60^{\mathrm{a}} \pm 2,09$ & $4,58^{\mathrm{a}} \pm 2,20$ & $4,47^{a} \pm 2,36$ & $4,87^{a} \pm 2,35$ \\
\hline $\begin{array}{l}\text { Odor carne assada } \\
\text { Roasted meat aroma }\end{array}$ & $7,67^{a} \pm 0,84$ & $7,37^{\mathrm{ab}} \pm 0,88$ & $7,15^{\mathrm{b}} \pm 1,33$ & $7,15^{\mathrm{b}} \pm 1,20$ \\
\hline $\begin{array}{l}\text { Textura } \\
\text { Texture }\end{array}$ & $7,33^{a} \pm 0,54$ & $7,22^{\mathrm{ab}} \pm 0,72$ & $6,65^{\mathrm{b}} \pm 2,03$ & $6,85^{\mathrm{ab}} \pm 1,68$ \\
\hline $\begin{array}{l}\text { Maciez } \\
\text { Tenderness }\end{array}$ & $7,85^{\mathrm{a}} \pm 0,55$ & $7,45^{\mathrm{ab}} \pm 0,77$ & $7,17^{b} \pm 1,14$ & $7,35^{\mathrm{b}} \pm 1,45$ \\
\hline $\begin{array}{l}\text { Sabor } \\
\text { Flavour }\end{array}$ & $7,65^{\mathrm{a}} \pm 0,66$ & $7,42^{a b} \pm 0,53$ & $7,05^{\mathrm{b}} \pm 1,47$ & $7,33^{\mathrm{ab}} \pm 1,28$ \\
\hline $\begin{array}{l}\text { Suculência } \\
\text { Juiciness }\end{array}$ & $7,37^{a} \pm 0,66$ & $7,65^{\mathrm{a}} \pm 0,68$ & $6,57^{b} \pm 1,39$ & $6,73^{\mathrm{b}} \pm 1,35$ \\
\hline
\end{tabular}

${ }_{1}^{1}$ Médias seguidas por letras distintas nas linhas, diferem $(\mathrm{P}<0,05)$ entre si pelo teste Tukey.

${ }^{1}$ Means with different letters within the same line differ $(P<.05)$ by Tukey test.

Vale citar que, além do atributo sensorial "odor ovino", que recebeu pontuação variando de 4,5 a 4,9 , os demais atributos foram pontuados com valores de 6,5 a 7,8; o que indica a boa qualidade da carne de ovinos Santa Inês, no que se refere aos parâmetros sensoriais.

Os percentuais de fosfolipídios e de colesterol sofreram influência do fator alimentação. As médias de colesterol variaram de 44,10 a 57,80 mg/100 g e os de fosfolipídios de 13,39 a 21,67 mg/100 g na carne de ovinos Santa Inês. Cordeiros alimentados com silagem de milho apresentaram carne com teores de colesterol e fosfolipídios mais reduzidos. Todavia, carnes com menores percentuais de gordura tiveram maior percentuais de colesterol e corresponderam a animais alimentados com palma forrageira, ressaltando que o menor peso de abate foi conferido para os animais deste grupo. Perez et al (2002) também observaram teores de colesterol mais elevados em cordeiros Santa Inês e Bergamácia, que apresentaram menores pesos. Perez et al. (2002), Kowale \& Kesava (1996), Lough et al. (1992), Solomon et al. (1991) verificaram, em carne de ovinos de outras raças, valores de colesterol superiores aos da presente pesquisa. 
Os valores de fosfolipídios obtidos foram inferiores $(13,39$ a $21,67 \mathrm{mg} / 100 \mathrm{~g})$ aos reportados por Kowale \& Kesava (1996) em carne de cordeiro $(56,7 \mathrm{mg} / 100 \mathrm{~g})$, não sendo encontradas justificativas para estas diferenças, exceto a metodologia analítica.

Os coeficientes de correlação de Pearson entre as características dos componentes lipídicos da carne de ovinos terminados com diferentes dietas encontram-se na Tabela 2. Não foi observada correlação significativa $(\mathrm{P}>0,05)$ entre as variáveis lipídios e fosfolipídios, nem entre os teores de fosfolipídios e colesterol, no entanto, os percentuais de gordura e de colesterol apresentaram correlação negativa e significativa a $1 \%$ de probabilidade. Mesma correlação foi observada por Rowe (1998) em cordeiros alimentados com pasto em regime extensivo e animais confinados, alimentados com concentrado.

Os dados referentes à qualidade química e sensorial da carne de cordeiros Santa Inês refletem as condições de restrição alimentar durante a fase de terminação. Os cordeiros alimentados com palma forrageira apresentaram os mais baixos pesos ao abate, em conseqüência da rejeição à alimentação.

Mesmo não havendo diferença significativa entre os tratamentos para as variáveis $\mathrm{L}^{*}, \mathrm{a}^{*} \mathrm{e} \mathrm{b*}$, a carne de ovinos Santa Inês apresentou-se mais escura (39,76 a 42,96), menos vermelha $(12,81$ a 14,22$)$ e mais pálida $(9,04$ a 10,16) quando comparada à de cordeiros com diferentes pesos de carcaça (Sañudo et al. (1992), cujos valores médio foram $L^{*}(48,15$ a 45,61), $a^{*}(13,94$ a 16,95$)$ e b* $(5,90$ a 6,02$)$. No entanto, a cor da carne foi mais clara quando comparada aos valores de $L^{*}(32,58$ a 32,78$)$ reportados por Perez et al. (1997), em cordeiros Santa Inês e Bergamácia.

O perfil dos ácidos graxos geralmente apresenta pouca influência no valor comercial da carcaça em comparação ao conteúdo de gordura. Entretanto, as

Tabela 2 - Coeficiente de correlação de Pearson entre os componentes lipídicos da carne de ovinos

Table 2 - Pearson coefficient correlation among the fat components of lamb meat

\begin{tabular}{lcc}
\hline $\begin{array}{l}\text { Variável } \\
\text { Variable }\end{array}$ & $\begin{array}{l}\text { Fosfolipídios } \\
\text { Phospholipids }\end{array}$ & $\begin{array}{l}\text { Colesterol } \\
\text { Cholesterol }\end{array}$ \\
\hline $\begin{array}{l}\text { Lipídeos } \\
\text { Lipids }\end{array}$ & $-0,0673^{\text {ns }}$ & $-0,5896^{* *}$ \\
Fosfolipídios & & $+0,0712^{\text {ns }}$ \\
Phospholipids & & \\
\hline
\end{tabular}

propriedades físicas e químicas dos lipídios afetam as características nutricionais, sensoriais e de conservação da carne (Mottram, 1998).

O perfil dos ácidos graxos da carne de cordeiros Santa Inês terminados com diferentes dietas foi constituído por 18 ácidos graxos (Tabela 3), que representam a soma dos ácidos graxos presentes nos fosfolipídios e na fração lipídica neutra, compostos por triacilglicerídeos e por quantidades pequenas de ácidos graxos livres.

Entre o total de ácidos graxos identificados, seis ácidos graxos (C18:1, C18:0, C16:0, C18:2, C16:1 e C18:2) constituíram acima de $90 \%$ das áreas totais dos cromatogramas. O ácido oléico (C18:1) foi o ácido graxo insaturado que mais contribuiu para o perfil dos ácidos graxos, enquanto os ácidos palmítico (C16:0) e esteárico (C18:0) contribuíram mais intensamente entre os ácidos graxos saturados. Tendência similar de perfil de ácidos graxos em longissimus dorsi de cordeiros resultantes do cruzamento entre as raças Ile de France x Corriedale foi apresentada por Monteiro \& Shimokomaki (1997).

Considerando que a concentração plasmática de colesterol é influenciada pela composição de ácidos graxos da dieta e sabendo-se que o ácido graxo palmítico (C16:0) aumenta o nível de colesterol sangüíneo, ao passo que o ácido oléico (C18:1) o diminui e que o ácido esteárico (C18:0) não exerce influência, observou-se que as dietas utilizadas no sistema de terminação não exerceram influência significativa sobre as concentrações destes três ácidos.

As somas dos ácidos graxos saturados (AGS) e a dos ácidos graxos poliinsaturados (AGPI) sofreram influência significativa das diferentes dietas testadas. Ovinos alimentados com palma forrageira apresentaram os somatórios mais elevados para os ácidos graxos saturados e poliinsaturados.

Banskalieva et al. (2000) e Rhee (1992) reportaram médias de ácidos graxos desejáveis (AGD) na carne de ovinos, de 64 a 72 . Na carne de cordeiros Santa Inês, os percentuais de AGD variaram de 70,27 a 72,48 (Tabela 3), observando-se concordância dos resultados com os valores da literatura. Esses autores defendem que a relação $(\mathrm{C} 18: 0+\mathrm{C} 18: 1)$ : C16:0 descreve os possíveis efeitos benéficos dos diferentes lipídios encontrados nas carnes vermelhas, com valores de 2,1 a 2,8 para a carne ovina. No presente trabalho, os resultados variaram de 2,53 a 2,76, confirmando a qualidade da fração lipídica de cordeiros Santa Inês (Banskalieva et al., 2000; Rhee, 1992). 
Tabela 3 - Médias das áreas dos picos de ácidos graxos da carne de ovinos Santa Inês Table 3 - Means of areas from fatty acids peaks from Santa Inez lamb meat

\begin{tabular}{|c|c|c|c|c|}
\hline \multirow[b]{2}{*}{$\begin{array}{l}\text { Componente } \\
\text { Component }\end{array}$} & \multicolumn{4}{|c|}{ Dietas (Diets) } \\
\hline & $\begin{array}{c}\text { Capim-d'água } 1 \\
\text { (T1) } \\
\text { Capim-d'água } \\
\text { hay (T1) }\end{array}$ & $\begin{array}{l}\text { Restolho de } \\
\text { abacaxi }^{1}(\mathrm{~T} 2) \\
\text { Pineapple } \\
\text { hay }(T 2)\end{array}$ & $\begin{array}{c}\text { Palma } \\
\text { forrageira }^{1}(\mathrm{~T} 3) \\
\text { Forage } \\
\text { palm }(\mathrm{T} 3)\end{array}$ & $\begin{array}{c}\text { Silagem de } \\
\text { milho }^{1}(\mathrm{~T} 4) \\
\text { Maize ensilage } \\
\text { hay (T4) }\end{array}$ \\
\hline Saturados & $48,43^{a b} \pm 5,89$ & $47,96^{\mathrm{b}} \pm 1,19$ & $50,51^{\mathrm{a}} \pm 1,75$ & $47,18^{b} \pm 2,22$ \\
\hline \multicolumn{5}{|l|}{ Saturated } \\
\hline C10:0 & $0,36^{\mathrm{a}} \pm 0,30$ & $0,09^{\mathrm{a}} \pm 0,02$ & $0,16^{\mathrm{a}} \pm 0,06$ & $0,13^{a} \pm 0,01$ \\
\hline $\mathrm{C} 12: 0$ & $0,10^{\mathrm{a}} \pm 0,06$ & $0,08^{\mathrm{a}} \pm 0,01$ & $1,91^{\mathrm{a}} \pm 1,74$ & $0,19^{a} \pm 0,02$ \\
\hline $\mathrm{C} 14: 0$ & $2,14^{\mathrm{a}} \pm 0,42$ & $2,75^{\mathrm{a}} \pm 0,19$ & $1,97^{\mathrm{a}} \pm 0,15$ & $2,54^{\mathrm{a}} \pm 0,35$ \\
\hline C15:0 & $0,79^{\mathrm{a}} \pm 0,40$ & $0,39^{a} \pm 0,04$ & $0,55^{\mathrm{a}} \pm 0,08$ & $0,51^{\mathrm{a}} \pm 0,09$ \\
\hline C16:0 & $24,14^{\mathrm{a}} \pm 3,70$ & $24,80^{\mathrm{a}} \pm 0,57$ & $22,08^{a} \pm 1,05$ & $23,11^{\mathrm{a}} \pm 0,61$ \\
\hline $\mathrm{C} 17: 0$ & $1,06^{\mathrm{b}} \pm 0,24$ & $1,43^{\mathrm{ab}} \pm 0,07$ & $2,52^{\mathrm{a}} \pm 0,48$ & $1,30^{\mathrm{b}} \pm 0,19$ \\
\hline C18:0 & $19,84^{\mathrm{a}} \pm 3,64$ & $18,42^{\mathrm{a}} \pm 1,10$ & $20,76^{\mathrm{a}} \pm 0,85$ & $19,14^{\mathrm{a}} \pm 1,84$ \\
\hline C20:0 & nd & nd & $0,56^{\mathrm{a}} \pm 0,44$ & $0,26^{\mathrm{a}} \pm 0,13$ \\
\hline Monoinsaturados & $47,59^{\mathrm{a}} \pm 8,88$ & $51,81^{\mathrm{a}} \pm 1,80$ & $44,50^{\mathrm{a}} \pm 1,92$ & $48,00^{\mathrm{a}} \pm 2,75$ \\
\hline \multicolumn{5}{|l|}{ Unsaturated } \\
\hline C14:1 & $1,71^{\mathrm{a}} \pm 1,18$ & $0,74^{\mathrm{a}} \pm 0,12$ & $0,07^{\mathrm{a}} \pm 0,07$ & $0,27^{\mathrm{a}} \pm 0,18$ \\
\hline C15:1 & $0,22^{\mathrm{a}} \pm 0,09$ & $0,20^{\mathrm{a}} \pm 0,03$ & $0,55^{\mathrm{a}} \pm 0,17$ & $0,41^{\mathrm{a}} \pm 0,06$ \\
\hline C16:1 & $3,44^{\mathrm{a}} \pm 0,95$ & $3,34^{\mathrm{a}} \pm 0,26$ & $2,43^{\mathrm{a}} \pm 0,20$ & $2,76^{\mathrm{a}} \pm 0,56$ \\
\hline $\mathrm{C} 17: 1$ & $0,84^{\mathrm{a}} \pm 0,28$ & $1,13^{\mathrm{a}} \pm 0,09$ & $1,36^{\mathrm{a}} \pm 0,18$ & $1,35^{\mathrm{a}} \pm 0,36$ \\
\hline C18:1 & $41,38^{a} \pm 9,07$ & $46,40^{\mathrm{a}} \pm 2,07$ & $40,09^{a} \pm 2,30$ & $43,15^{\mathrm{a}} \pm 2,32$ \\
\hline C20:1 & $\mathrm{Nd}$ & nd & nd & $0,06 \pm 0,03$ \\
\hline Poliinsaturados & $3,02^{a b} \pm 0,55$ & $2,25^{\mathrm{b}} \pm 0,24$ & $5,01^{\mathrm{a}} \pm 0,69$ & $4,84^{\mathrm{a}} \pm 0,56$ \\
\hline \multicolumn{5}{|l|}{ Poli-unsaturated } \\
\hline C18:2 & $2,22^{b} \pm 0,57$ & $1,67^{\mathrm{b}} \pm 0,12$ & $3,16^{\mathrm{ab}} \pm 0,31$ & $3,88^{\mathrm{a}} \pm 0,34$ \\
\hline C18:3 & $0,80^{\mathrm{ab}} \pm 0,20$ & $0,33^{\mathrm{b}} \pm 0,04$ & $1,32^{\mathrm{a}} \pm 0,35$ & $0,64^{\mathrm{ab}} \pm 0,09$ \\
\hline $\mathrm{C} 20: 3$ & $\mathrm{Nd}$ & $\mathrm{Nd}$ & $0,53^{a} \pm 0,27$ & $0,20^{\mathrm{a}} \pm 0,15$ \\
\hline C20:4 & $\mathrm{Nd}$ & $0,25^{\mathrm{a}} \pm 0,15$ & nd & $0,12^{\mathrm{a}} \pm 0,12$ \\
\hline AGPI:AGS & $0,06^{\mathrm{b}} \pm 0,01$ & $0,05^{\mathrm{b}} \pm 0,01$ & $0,10^{\mathrm{a}} \pm 0,01$ & $0,10^{\mathrm{a}} \pm 0,01$ \\
\hline \multicolumn{5}{|l|}{ PUFA:SFA } \\
\hline AGPI:AGMI & $0,06^{\mathrm{b}} \pm 0,01$ & $0,04^{\mathrm{b}} \pm 0,00$ & $0,11^{\mathrm{a}} \pm 0,02$ & $0,10^{\mathrm{a}} \pm 0,02$ \\
\hline \multicolumn{5}{|l|}{ PUFA:MUFA } \\
\hline AGMI:AGS & $0,98^{\mathrm{a}} \pm 0,09$ & $1,08^{\mathrm{a}} \pm 0,06$ & $0,89^{b} \pm 0,07$ & $1,03^{\mathrm{a}} \pm 0,11$ \\
\hline \multicolumn{5}{|l|}{ MUFA:SFA } \\
\hline $\mathrm{AGD}^{2}$ & $70,45^{\mathrm{a}}$ & $72,48^{\mathrm{a}}$ & $70,27^{\mathrm{a}}$ & $71,98^{\mathrm{a}}$ \\
\hline \multicolumn{5}{|l|}{$D F A$} \\
\hline$(\mathrm{C} 18: 0+\mathrm{C} 18: 1): \mathrm{C} 16: 0$ & $2,53^{\mathrm{a}}$ & $2,61^{\mathrm{a}}$ & $2,76^{\mathrm{a}}$ & $2,69^{\mathrm{a}}$ \\
\hline
\end{tabular}

\footnotetext{
${ }_{1}^{1}$ Médias seguidas por letras distintas nas linhas, diferem $(P<0,05)$ pelo teste Tukey.

${ }^{1}$ Means with different letters within the same line differ by Tukey test $(P<.05)$.

${ }^{2}$ AGD (ácidos graxos desejáveis $=\mathrm{AGMI}+\mathrm{AGPI}+\mathrm{C} 18: 0$ ).

2 DFA (desirable fatty acids = MUFA + PUFA + C18:0).
}

\section{Conclusões}

A utilização de quatro tipos de volumosos exerceu influência significativa sobre os teores de composição centesimal, cálcio, fósforo, colesterol, fosfolipídios, ácidos graxos saturados, poliinsaturados e sobre os parâmetros sensoriais da carne de ovinos Santa Inês.

Os animais alimentados com palma forrageira (T3) produziram carnes com teores elevados de colesterol, ácidos graxos saturados, percentuais re- duzidos de gorduras, ácidos graxos monoinsaturados e qualidade sensorial inferior à carne dos animais dos demais tratamentos.

Os animais alimentados com volumosos contendo capim-d'água (T1), restolho de abacaxi (T2) e silagem de milho (T4) apresentaram carne ovina de melhor qualidade, em função das baixas concentrações de colesterol e ácidos graxos saturados e do alto teor de ácidos graxos monoinsaturados, mesmo apresentando os maiores teores de lipídios. 


\section{Agradecimento}

Ao CNPq e à CAPES, pelo apoio financeiro e pelas bolsas concedidas.

À EMEPA/PB, pelo fornecimento dos animais em estudo.

\section{Literatura Citada}

AMARINE, M.A.; PANGBORN, M.R.; ROESSLER, E.B. Principles of sensory evaluation off. New York: Academic Press, 1965. 602p.

ASSOCIATION OF ANALITICAL CHEMISTS - AOAC. Official methods of analysis of AOAC International. 19.ed. Washington, D.C.: AOAC Intenrational, 2000. 1219p.

BANSKALIEVA, V.; SAHLU, T.; GOETSCH, A.L. Fatty acid composition of goat muscles and fat depots - a review. Small Ruminant Research, v.37, p.255-268, 2000.

BOHAC, C.E., RHEE, K.S., ONO, K. Assessment of methodologies for colorimetric cholesterol assay of meats. Journal Food Science, v.53, p.1642-1693, 1988.

BRASIL. MINISTÉRIO DA AGRICULTURA. Regulamento da Inspeção industrial e Sanitária de Produtos de Origem Animal. Brasília, DF:MA, 1997.

BRESSAN, M.C., PRADO, O.V., PEREZ, J.R.O., LEMOS, A.L.S.C, BONAGURIO, S. Efeito do peso ao abate de cordeiros Santa Inês e Bergamácia sobre as características físico-químicas da carne. Ciência e Tecnologia de Alimentos, v.21, n.3, p. 293-303, 2001.

EGAN, H.; KIRK, R.S.; SAWYER, R. Pearson's chemical analysis of foods. 8.ed. London: Churchill Livingstone, 1981. 591p.

FOLCH, J.; LESS, M.; STANLEY, S. A simple method for the isolation and purification of total lipids from animal tissues. Journal Biology Chemistry, v.226, p.497-509, 1957.

HARTMAN, L.; LAGO, B.C. A rapid preparation of fatty acid methyl esters from lipids. Laboratory Practice, v.22, p.475477, 1973.

KOWALE, B.N.; KESAVA, R.V.L. Lipid oxidation and cholesterol oxidation in mutton during cooking and storage. Meat Science, v.43, p.195-202, 1996.

LARMOND, E. Laboratory methods for evaluation of foods. Ottawa: Food Research Institute/Canada Department of Agriculture, 1977. 432p.

LOUGH, M.D.; MULLER, L.; RUSSO, J. Effects of dietary canola seed and soylecithin in high-forage diets on cholesterol content and fatty acid composition of carcass tissues of growing ram lambs. Journal of Animal Science, v.70, p.11531158, 1992.

MADRUGA, M.S. Revisão: formação do aroma cárneo. Boletim da Sociedade Brasileira de Ciência e Tecnologia de Alimentos, n.31, v.1, p.33-41, 1997.

MADRUGA, M.S.; ARRUDA, S.G.B.; NARAIN, N. et al. Castration and slaughter age effects on panel assessment and aroma compounds of the "mestiço" goat meat. Meat Science, v.56, p.117-125, 2000.

MADRUGA, M.S.; NARAIN, N.; COSTA, R.G. Influência da idade de abate e da castração nas qualidades fisico-químicas sensoriais e aromáticas da carne carpina. Revista Brasileira de Zootecnia, v.31, n.3, p.1562-1570, 2002.
MONTEIRO, E.M.; SHIMOKOMAKI,M. Influência da raça no perfil dos ácidos graxos na carne de cordeiros. CONGRESSO BRASILEIRO DE CIÊNCIA E TECNOLOGIA DE ALIMENTOS, 16., 1997, Rio de Janeiro. Anais... Rio de Janeiro: Sociedade Brasileira de Ciência e Tecnologia de Alimentos, 1997. v.2, p.1328-1331.

MOTTRAM, D.S. Flavour formation in meat and meat products: a review. Food Chemistry, v.62, n.4, p.415-424, 1998.

MULLER, L. Normas para avaliação de carcaças e consumo de carcaças de novilhos. Santa Maria: Universidade Federal de Santa Maria. 1980. 32p.

NATIONAL RESEARCH COUNCIL - NRC. Nutrient requirement of sheep. 6.ed. Washington, D.C.: National Academy of Science, 1985. 99p.

PEREZ, J.R.O. Perspectivas da ovinocultura nas regiões sudeste e centro-oeste do Brasil. In: SIMPÓSIO INTERNACIONAL SOBRE CAPRINOS E OVINOS DE CORTE, 2., 2003, João Pessoa. Anais...João Pessoa: EMEPA, 2003. v.1, p.243-262.

PEREZ, J.R.O.; BRESSAN, M.C.; BRAGAGNOLO, N. et al. Efeito do peso ao abate de cordeiros Santa Inês e Bergamácia sobre o perfil de ácidos graxos, colesterol e propriedades químicas. Ciência e Tecnologia de Alimentos, v.22, n.1, p.11-18, 2002.

PEREZ, J.R.O.; BONAGURIO, S.; BRESSAN, M.C. et al. Efeitos dos dejetos de suínos na qualidade da carne de ovinos. In: REUNIÃO DA SOCIEDADE BRASILEIRA DE ZOOTECNIA, 34. , 1997, Juiz de Fora. Anais... Juiz de Fora: Sociedade Brasileira de Zootecnia, 1997, v.1, p.391.

RHEE, K.S. Fatty acids in meats and meat products. In: CHOW, C.K. (Ed.) Fatty acids in Foods and their health implications. New York: Marcel Dekker, 1992. p.65-93.

ROWE, A. Composição da carne de cordeiros de diferentes grupos genéticos terminados em pastagens ou confinamento. Maringá: Universidade Estadual de Maringá, 1998. 85p. Dissertação (Mestrado em Zootecnia) - Universidade Estadual de Maringá, 1998.

SAÑUDO, C.; SIERRA, I.; ALCALDE, M.J. Calidad de la canal en corderos ligeros tipo ternasco, canales españolas y de importación. ITEA, v.88, p.88-94, 1992.

SIMPLÍCIO, A.A. A caprino-ovinocultura na visão do agronegócio. Revista CFMV, n.24, p.15-18, 2001.

SOLOMON, M.B.; KEMP, J.D.; FOX, J.D. et al. Influence of rapeseed meat, whole rapeseed and soybeans meal on fatty acid composition and cholesterol content in muscle and adipose tissue from ram lambs. Journal of Animal Science, v.69, p.40554061, 1991.

SOUSA, W.H. Genetic and environmental factors affecting growth and reprodutive performance of Santa Ines sheep on the semi-arid region of Brazil. Texas: University College Station, 1987.98p. (MSc Thesis) - University College Station, 1987.

STEEL, R.G.D.; TORRIE, J.H. Principles and procedures of statistics. New York: McGraw-Hill, 1980. 481p.

ZEOLA, N.M. Composição química da carne ovina. Revista Nacional da Carne, ano 25, n.292, p.36-48, 2001.

ZEOLA, N.M. Conceitos e parâmetros utilizados na avaliação da qualidade da carne ovina. Revista Nacional da Carne, ano 26, n.304, p.32-44, 2002.

Recebido em: 04/03/04

Aceito em: 20/09/04 